\title{
New Geometries for Calix[6]arene-based Rotaxanes
}

\author{
Margherita Bazzoni, ${ }^{[\mathrm{a}]}$ Valeria Zanichelli, ${ }^{[\mathrm{a}]}$ Lorenzo Casimiro, ${ }^{[\mathrm{b}]}$ Chiara Massera,${ }^{[\mathrm{a}]}$ Alberto Credi, ${ }^{[\mathrm{c}, \mathrm{d}]}$ \\ Andrea Secchi, ${ }^{* a]}$ Serena Silvi, ${ }^{*[b]}$ and Arturo Arduini ${ }^{*[a]}$
}

\begin{abstract}
Understanding the role played by the nature, number and arrangement of binding sites anchored to a macrocycle remains a topic of current interest for the synthesis of new interwoven species. We report the synthesis and detailed structural characterisation of a new calix[6]arene derivative decorated with two phenylureido groups anchored at the diametrical position of the calix upper rim that adopts a 1,2,3-alternate conformation in solution and in the solid state. Preliminary data on the ability of this host to form redox-active pseudorotaxanes and rotaxanes are reported.
\end{abstract}

\section{Introduction}

The nature, number and reciprocal orientation of the binding sites that characterise either natural and synthetic receptors are responsible for their ability to efficiently bind a target guest and perform a programmed function. During these last decades, the supramolecular approach has led to the construction of several stimuli-responsive devices and prototypes of molecular machines that paved the way for the bottom-up approach to the development of nanotechnology. ${ }^{[1-3]}$ Within this context, calix[6]arenes have demonstrated to be a versatile platform ${ }^{[4,5]}$ for the construction of interwoven aggregates belonging to the class of pseudorotaxanes and rotaxanes. ${ }^{[6,7]}$ During the last two decades, we showed that, in apolar media, the tris- $(N$ phenylureido) calix[6]arene TPU can take up 4,4'-bipyridinium (viologen) salts and form pseudorotaxanes in a process in which the phenylurea groups at the upper rim of the calixarene play a crucial role in pivoting the unidirectional threading of the cationic viologen through the macrocycle upper rim. $^{[8-11]}$ This process paved the way for the synthesis of oriented (pseudo)rotaxanes,

[a] M. Bazzoni, Dr. V. Zanichelli, Prof. C. Massera, Prof. A. Secchi, Prof. A. Arduini

Dipartimento di Scienze Chimiche, della Vita e della Sostenibilità Ambientale

Università di Parma

Parco Area delle Scienze 17/A, I-43124 Parma, Italy

E-mail:

[b] Lorenzo Casimiro, Dr. S. Silvi

Dipartimento di Chimica "G. Ciamician",

Università di Bologna

Via Selmi 2, I-40126, Italy

[c] Prof. Alberto Credi

Center for Light Activated Nanostructures (CLAN) and Dipartimento di Scienze e Tecnologie Agro-alimentari, Università di Bologna, 40127 Bologna, Italy

[d] Istituto per la Sintesi Organica e la Fotoreattività (ISOF) - CNR Area della Ricerca di Bologna - Via P. Gobetti 101 - 40129 Bologna - Italy 40129 Bologna, Italy

Supporting information for this article is given via a link at the end of the document. characterised by the univocal orientation of the thread termini with respect to the two calix[6]arene rims. ${ }^{[12-18]}$

A retrospective perusal of the solid state structure of pseudorotaxane TPU $\supset$ DOV, formed by TPU and dioctylviologen diiodide $(\mathbf{D O V} \times 2 \mathrm{I})$ (see the schematic representation of Figure 1), ${ }^{[8]}$ clearly shows the calix[6]arene macrocycle adopting a flattened cone conformation in which a defined $\pi$-rich aromatic cavity surrounds the viologen bipyridinium dication, while both the iodide counteranions are $\mathrm{H}$-bonded to the ureido moieties at the upper rim of TPU. However, while the anion involved in $\mathrm{H}$-bonds with two urea moieties is completely separated from its pyridinium counteranion deeply engulfed inside the aromatic cavity, the other, bound by only one urea, remains in intimate contact with the pyridinium ring protruding from it. Nevertheless, the role played by the number and reciprocal position of the phenylurea binding sites anchored at the calix[6]arene platform and its ability to behave as a wheel for pseudorotaxanes and rotaxanes remains unexplored.

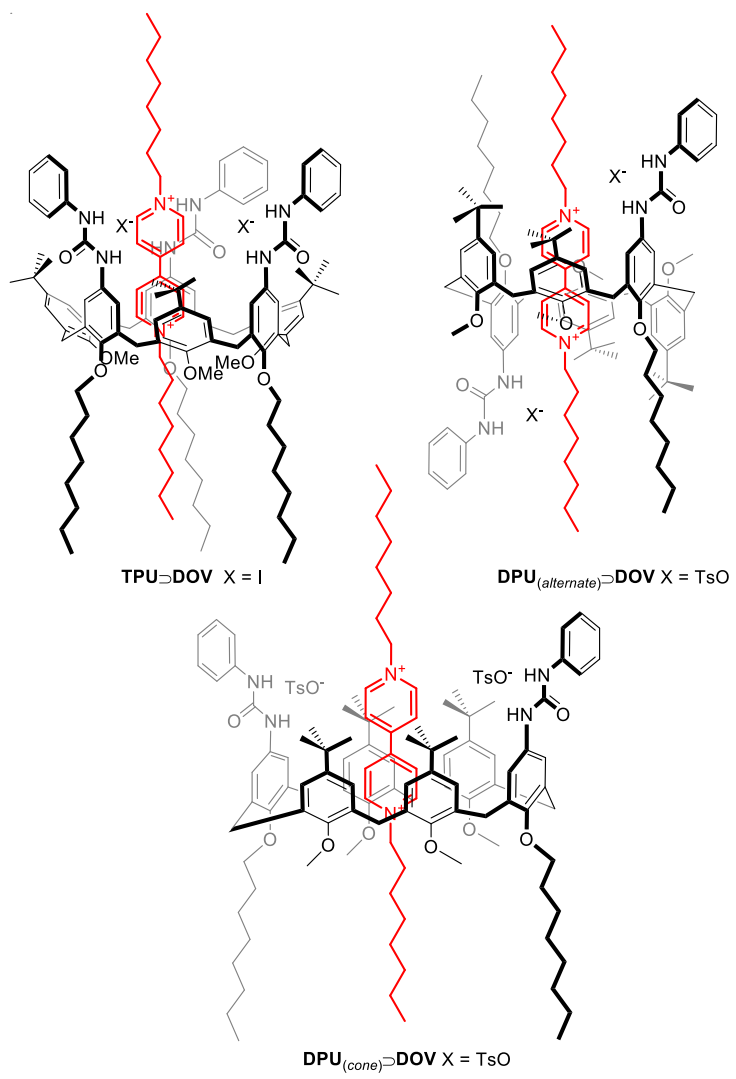

Figure 1. Schematic representation of the interwoven structures formed between tris- and bis-( $N$-phenylureido) calix[6]arene derivatives, TPU and DPU, respectively, and viologen salts. 
Van Duynhoven et al. have shown that in low polarity solvents 1,3,5-trimethoxy-2,4.6-trialkoxy-para-tert-butylcalix[6]arenes can slowly interconvert from their flattened cone conformation to their 1,2,3-alternate conformation. ${ }^{[19]}$ The two conformations are coexistent at room temperature, one slowly interconverting to the other. Such behaviour was explained considering an intraannulus interconversion of the tert-butyl groups. The potential of the calix[6]arene platform to orient its skeleton and to wrap around a specific guest was recently evidenced by Jabin and coworkers. ${ }^{[20]}$ Inspired by these studies, we imagined that the latter geometrical arrangement decorated with $\mathrm{H}$-bond-donor groups like phenylureas might promote the formation of pseudorotaxanes and rotaxanes endowed with new properties.

In this paper we present our efforts aimed at the synthesis of a novel hexa-O-alkylated heteroditopic calix[6]arene receptor (DPU) characterised by two octyloxy and four methyloxy groups in 1,4 and 2,3,5,6 positions, respectively. Two diametric $N$ phenylureido moieties in para with respect to the octyloxy groups complete the structure of the receptor (see Scheme 1). The objective of the work is also to investigate the conformational preference adopted by this receptor in solution and in the solid state and to establish whether the addition of viologen salts as guests would lead to interwoven structures.

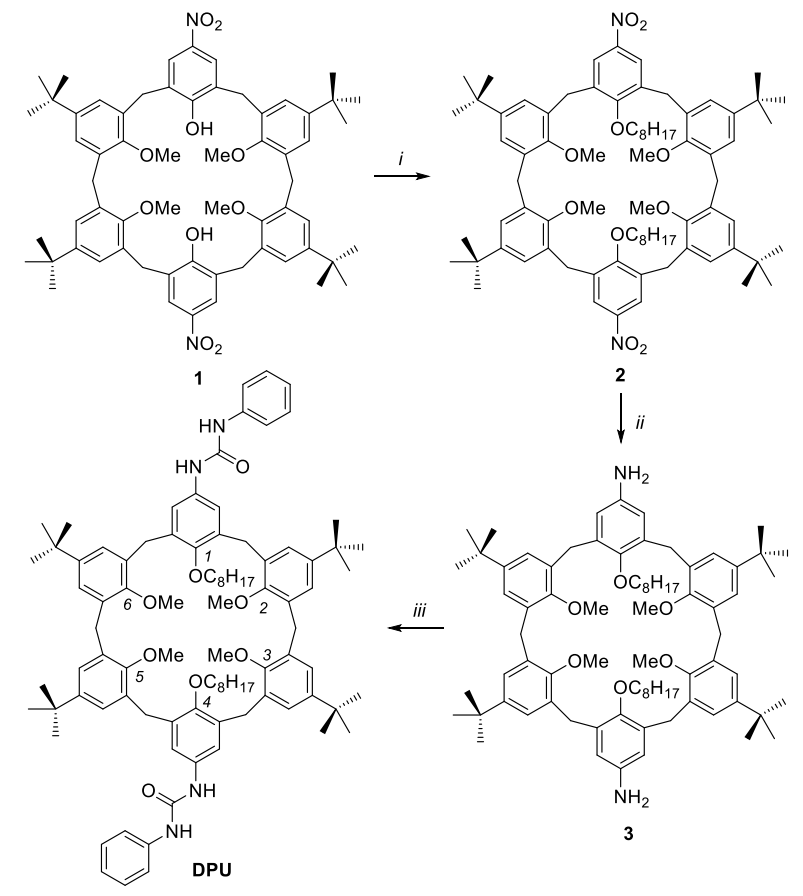

Scheme 1. Reagents and conditions: i) 1-lodooctane, $\mathrm{K}_{2} \mathrm{CO}_{3}, \mathrm{CH}_{3} \mathrm{CN}$, reflux, 4d, 70\%; ii) $\mathrm{NH}_{2} \mathrm{NH}_{2} \cdot \mathrm{H}_{2} \mathrm{O}, \mathrm{Pd} / \mathrm{C}, \mathrm{EtOH}$, reflux, $24 \mathrm{~h}$ and iii) ) phenyl isocyanate, $\mathrm{CH}_{2} \mathrm{Cl}_{2}$, rt, $2 \mathrm{~h}, 80 \%$ (two steps).

\section{Results and Discussion}

\section{Synthesis of the Host}

To synthesise DPU, we started from the known tetramethoxydinitro calix[6]arene derivative 1 (see Scheme 1). ${ }^{[1]}$ Reaction of 1 with 1-iodooctane in refluxing acetonitrile using $\mathrm{K}_{2} \mathrm{CO}_{3}$ as base gave 2 that was isolated by precipitation from ethyl acetate in $70 \%$ yield. Its ${ }^{1} \mathrm{H}$ NMR spectrum, taken in $\mathrm{CDCl}_{3}$ (see Fig. $\mathrm{S} 1$, Supporting Information, $\mathrm{SI}$ ), shows, as diagnostic features, three broad signals in 1:1:1 integration ratio at $7.6,7.2$ and $7.0 \mathrm{ppm}$, for the aromatic protons, while in its mid-field region are recognizable: two broad doublets at 3.6 and $4.3 \mathrm{ppm}$, each integrating for 4 protons, two overlapped broad signals, overall integrating for 8 protons, at ca. $3.9 \mathrm{ppm}$, and a singlet at ca. 3.0 ppm integrating for 12 protons. Through routinely 2D COSY and HSQC NMR experiments (see Fig. S3, SI), the two broad doublets were assigned to an $\mathrm{AX}$ system of coupled germinal protons belonging to four of the six macrocycle bridging methylene groups. The two overlapped signals were resolved and assigned to the two remaining bridging methylenes, which are in this case magnetically equivalent, and to the two methylene groups nearby the phenolic oxygen in the two octyl chains, respectively. The singlet at $3 \mathrm{ppm}$ was finally assigned to the four methoxy groups. Its resonance is quite upfield-shifted $(\sim 1 \mathrm{ppm})$ with respect to its common values and, as seen with TPU ${ }^{[18]}$ and other trimethoxy calix[6]arene derivatives, ${ }^{[19]}$ this shift is usually explained as an anisotropic shielding effect exerted by the aromatic cavity of the macrocycle on vicinal methoxy groups. Despite the general broadness of the spectrum signals, which confirms a residual fluxionality of the calix[6]arene macrocycle on the NMR timescale, overall, the resulting signals pattern is consistent with a calix[6]arene macrocycle adopting, at room temperature, a 1,2,3alternate conformation. Reduction of the nitro groups with hydrazine using $\mathrm{Pd} / \mathrm{C}$ as catalyst leads to the formation of the diamino derivative 3 , which was not isolated but directly reacted with phenyl isocyanate to afford the target calix[6]arene DPU in $80 \%$ of overall yield.

The identity of DPU was established through high-resolution (TOF) mass spectroscopy (see Fig. S4, SI) and 1D and 2D NMR measurements (see Fig. S5-12, SI). The ${ }^{1} \mathrm{H}$ NMR spectrum, recorded in $\mathrm{CDCl}_{3}$ (see Fig. $\mathrm{S} 5, \mathrm{SI}$ ), exhibits several very broad resonances supporting the hypothesis that, like its precursor $\mathbf{2}$, also DPU experiences, on the NMR timescale, a certain fluxionality in solution. Through a perusal of the HSQC spectrum (see Fig. S9, SI) we were able to identify two sets of signals, each set of which likely belonging to two possible conformers simultaneously present in solution. In particular, we identified two resonances for the methoxy groups (a) (see Figure 2 for labelling), which give rise to a very broad peak at ca. $3.4 \mathrm{ppm}$ and a sharper singlet at $2.99 \mathrm{ppm}$, and two for the methylene groups $(b)$ of the octyl chains, that is, an intense triplet at $4.04 \mathrm{ppm}$ and a smaller one at $3.8 \mathrm{ppm}$. In the corresponding ${ }^{13} \mathrm{C}$-APT spectrum (see Fig. $\mathrm{S} 5, \mathrm{SI}$ ), the carbon nuclei of these groups yield, in the uncrowded spectral window between 50 and $80 \mathrm{ppm}$, two easily recognisable peaks for (a) at 60.2 and ca. $61 \mathrm{ppm}$ (one still very broad), and two for $(b)$ at 73.7 and $73.3 \mathrm{ppm}$.

The presence of two conformers in solution was subsequently confirmed by verifying the splitting of several other resonances of the proton spectrum. Among the several evidences, for example, in the upfield region of the 2D TOCSY spectrum (see Fig. S11, $\mathrm{SI}$ ), are easily identifiable two series of multiple correlations, each deriving from one of the conformers, starting from the resonances of the methylene group $(b)$ and propagating to the protons of the respective octyl chains (see Fig. S11, SI). It is important to note that the signals of the two conformers are in a 4:1 integration ratio (see infra). The analysis of the signals generated by the macrocycle bridging methylene groups was crucial to determine the geometry adopted by these conformers. As discussed in the introduction, it is known that 1,3,5-trimethoxy-2,4.6-trialkoxy-para- 
tert-butilcalix[6]arenes like TPU may adopt, in solution of low polarity solvents, other than the flattened cone conformation also the 1,2,3-alternate one. On the other hand, we have just verified that a 1,2,4,5-tetramethoxy derivative $\mathbf{2}$ is present in solution in the 1,2,3-alternate conformation. Therefore, we hypothesised that also DPU might adopt at least these two conformations (see Figure 2). In particular, we reasoned that, in the cone conformation $(\boldsymbol{C})$, the protons of the six bridging methylene groups of DPU would experience a different magnetic environment and because of the macrocycle symmetry would give rise to four doublets, with geminal coupling, two for the axial and two for the equatorial protons in the 2:1:1:2 ratio (see Figure 2). However, considering the different functionalisation of the aromatic nuclei, we postulated the existence of two different 1,2,3alternate conformations $-\boldsymbol{A}-1$ and $\boldsymbol{A - 2}$ (see Figure 2) - which differ for the position of the ring bearing the phenylurea groups with respect to the inversion points of the macroring. The bridging methylene groups of these two conformers, because of different symmetry of the macrocycle, would yield very different patterns of signals: conformer $\boldsymbol{A - 1}$ would give a simpler spectrum of two doublets (equatorial and axial) and a singlet - the bridging methylene (2) - in a 1:1:1 integration ratio. Contrariwise, $\boldsymbol{A}-\mathbf{2}$ would yield a very complicated pattern of 2 doublets, a singlet and two doublets in 1:1:2:1:1 integration ratio (see Figure 2 for further details).

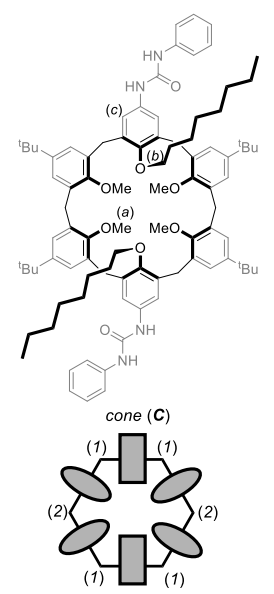

$\mathrm{d}(1-\mathrm{ax}): \mathrm{d}(2-\mathrm{ax}): \mathrm{d}(2-\mathrm{eq}): \mathrm{d}(1-\mathrm{eq})$

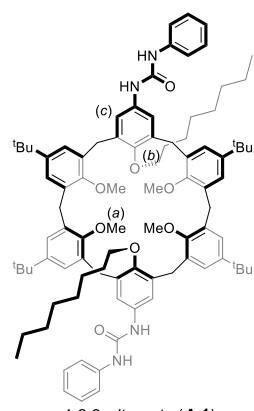

1,2,3-alternate (A-1)

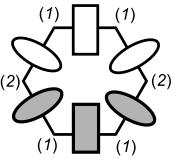

$\mathrm{d}(1-\mathrm{ax}): \mathrm{s}(2): \mathrm{d}(1-\mathrm{eq})$

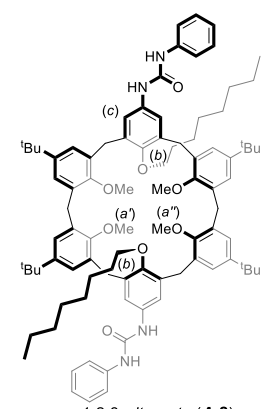

1,2,3-alternate (A-2)
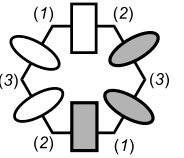

$\mathrm{d}(1-\mathrm{ax}): \mathrm{d}(2-\mathrm{ax}): \mathrm{s}(3): \mathrm{d}(1-\mathrm{eq}): \mathrm{d}(2-\mathrm{eq})$
Figure 2. Schematic representation of the three possible conformations adopted by DPU in $\mathrm{CDCl}_{3}$. The colour of the ovals/rectangles indicate the relative position of the phenolic substituent with respect to the plane defined by the bridging methylene groups (hexagon), i. e. grey upward, white downward. The rectangle identifies the phenolic ring substituted with the octyloxy chains, while the ovals those with the methoxy groups. The pattern of the NMR signals yielded by the protons of the bridging methylene groups in each conformation has been placed under the corresponding conformer schematic representation with the multiplicity (doublet or singlet) and relative integration ratio. When the protons are diastereotopic, their axial (ax) or equatorial (eq) geometrical arrangement has been indicated along with the multiplicity and type of methylene group [e.g. $d(1$-ax $)$ ].

Analysis of the 2D COSY and HSQC NMR spectra (see Fig. $\mathrm{S} 7-10, \mathrm{SI}$ ) showed that, as indicated by black circles in Figure 3 , the minor conformer affords two pairs of doublets at 4.31 and 4.1 ppm (axial) and 3.56 and 3.71 (equatorial). It thus seems quite clear that the minor conformer is in the cone conformation $(\boldsymbol{C})$. The major conformer yields instead a pair of doublets for the axial and equatorial methylene protons $\left({ }^{2} \mathrm{~J}=15 \mathrm{~Hz}\right)$ resonating at 4.1 and $3.8 \mathrm{ppm}$, respectively (see white circles in Figure 3 ), that is a pattern that did not match for anyone of the conformations proposed in Figure 2. Therefore, we carried out a variable temperature experiment (see Figure 3 ). The temperature rise did not affect the relative abundance of the two conformers (cf. the intensity of the methoxy resonances in Figure 3), but significantly increased the conformation mobility of the major conformer (see, e.g. the sharpening of the methoxy resonance at $3.4 \mathrm{ppm}$ ). Two other very broad resonances at ca. 6 and $4 \mathrm{ppm}$, barely recognisable at room temperature (see arrows in Figure 3), gradually become sharper as the temperature increases. An HSQC experiment carried out at $T=325 \mathrm{~K}$ (see Fig. S14, SI) finally allowed to assign these resonances, respectively, to the aromatic protons (c), and the bridging methylene group (2) of the macrocycle inversion points (see Figure 2). The correct pattern of signals for the bridging methylene units for the major conformer was thus identified as doublet/singlet/doublet in a 1/1/1 integration ratio. This pattern is consistent with the 1,2,3-alternate conformation $\mathbf{A}-\mathbf{1}$.

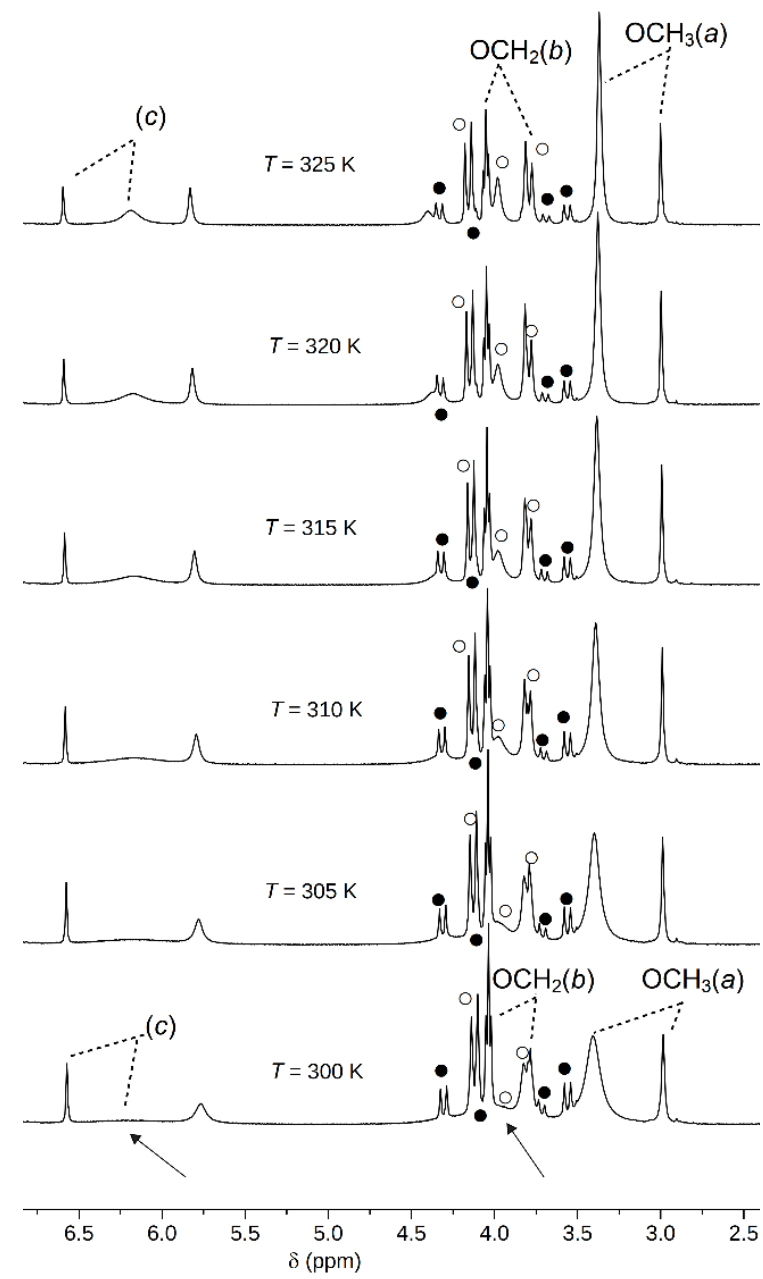

Figure 3. Stack plot of the variable temperature NMR experiment $(T=300 \rightarrow 325$ $\mathrm{K}$, expanded region, see Fig. S13, SI for the full spectral range) carried out on DPU $\left(400 \mathrm{MHz}, \mathrm{CDCl}_{3}\right)$. The resonances of the bridging methylene protons belonging to conformers $\boldsymbol{C}$ and $\boldsymbol{A}-\mathbf{1}$ (see Figure 2) have been labelled with black and white circles, respectively. Resonances marked as $(a),(b)$ and $(c)$ have been indicated on the molecular sketches of Figure 2. 


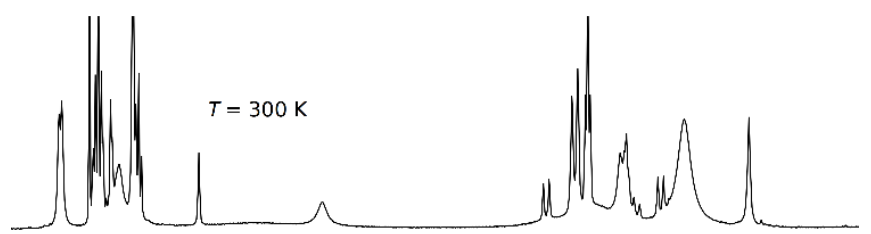

$T=283 \mathrm{~K}$

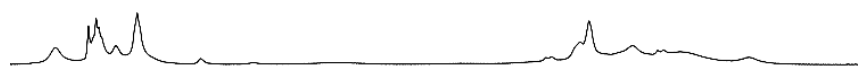

$T=260 \mathrm{~K}$
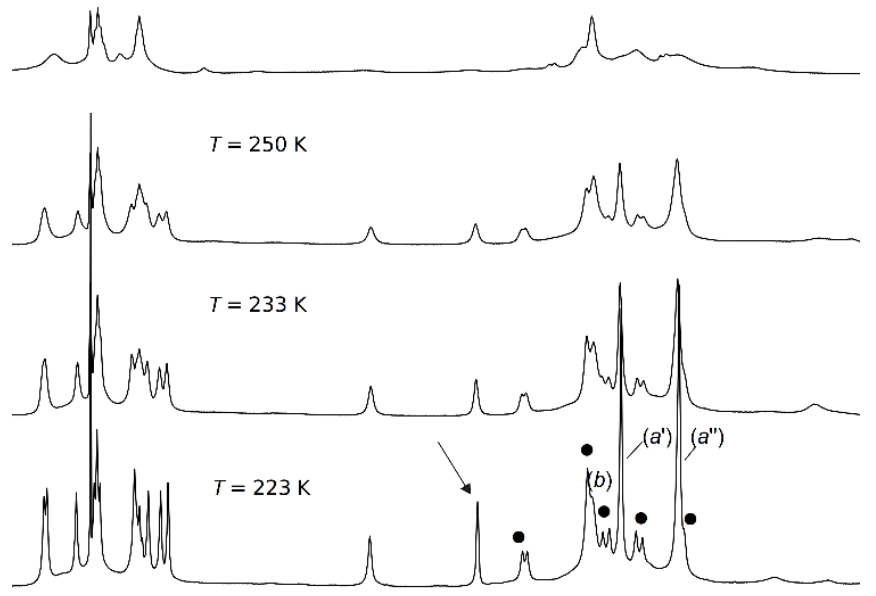

$\begin{array}{lllllllllll}7.5 & 7.0 & 6.5 & 6.0 & 5.5 & 5.0 & 4.5 & 4.0 & 3.5 & 3.0 & 2.5\end{array}$

Figure 4. Stack plot of the variable temperature NMR experiment $(T=300$ $\rightarrow 223 \mathrm{~K}$, expanded region, see Fig. S15, SI for the full range) carried out on DPU $\left(400 \mathrm{MHz}, \mathrm{CDCl}_{3}\right)$. The resonances of the bridging methylene protons belonging to conformers $\boldsymbol{A}-2$ (see Figure 2 ) have been labelled with black circles, respectively. Resonances marked as $(a)$ and $(b)$ have been indicated on the molecular sketches of Figure 2. The arrow highlights one the macrocycle aromatic protons resonating at unexpectedly high fields.

Encouraged by the previous findings, we wanted to check the effect of the temperature lowering on the mobility of the two conformations. The collection of spectra taken down to $T=223 \mathrm{~K}$ is gathered in the stack plot of Figure 4. Signals' coalescence was observed at $T=260 \mathrm{~K}$, while at $T=223 \mathrm{~K}$ they were sufficiently resolved to allow the accomplishment of an HSQC experiment (see Fig. S16, SI). The bridging methylene protons give rise to a pattern of two doublets (axial protons), one broad singlet and two doublets (equatorial protons). Although the central singlet is overlapped with that of the methylene protons (2), the integration ratio between the above resonances seems in agreement with the conformer indicated as $\boldsymbol{A - 2}$ in Figure 2. With respect to the $\boldsymbol{A - 1}$ geometry, in $\boldsymbol{A - 2}$ the rings bearing the phenylurea moiety are now shifted adjacent to the methylene bridging units joining the two half-parts of the macrocycle (see Figure 2). Two methoxy signals ( $a^{\prime}$ and $a^{\prime \prime}$ ), in 1:1 ratio, are visible in the spectrum at this temperature. One occurs at its usual fields $(\delta=3.83 \mathrm{ppm})$, while the other is up-field shifted of $\sim 0.4 \mathrm{ppm}$ ( $\delta=3.45 \mathrm{ppm}$ ). This suggests that one of the two methoxy groups experiences a higher shielding effect (vide infra, crystal structure discussion). Even more straightforward was the observation that one of the aromatic signals resonates at $4.78 \mathrm{ppm}$, which is unexpectedly largely up-field shifted $(22.5 \mathrm{ppm})$. This suggests that at this temperature some aromatic rings would be placed above the aromatic cavity. Reasonably, the only aromatic ring possessing sufficient mobility to experience such a shielding effect is that of the phenylurea moiety (vide infra). The resonances of the methoxy group (a) assigned to conformers $\boldsymbol{A}-1$ and $\boldsymbol{C}(\Delta v=148$ $\mathrm{Hz}$ at $T=325 \mathrm{~K}$ ) coalesce at $T=260 \mathrm{~K}$ (see Figure 4). From these data, an energy barrier $\Delta G^{\ddagger} \sim 28 \mathrm{~kJ} \mathrm{~mol}^{-1}$ for the interconversion between the conformers was determined. ${ }^{[19,22]}$

Finally, we planned to verify whether the $\mathrm{H}$-bond donor and acceptor nature of the phenylureas present in DPU could promote aggregation phenomena. We thus devised a simple NMR experiment: increasing amounts of deuterated methanol were added to a sample of DPU in $\mathrm{CDCl}_{3}$ kept at room temperature. The competition of the methanol for the $\mathrm{H}$-bonding lead to a progressive simplification of the NMR spectrum (see Figure 5) with an upfield shift of the resonances of the methoxy (a) and methylene $(b)$ groups of the major conformer $(\boldsymbol{A}-\mathbf{1})$. Although less marked, a similar upfield shift was also found for the corresponding resonances of the minor conformer.

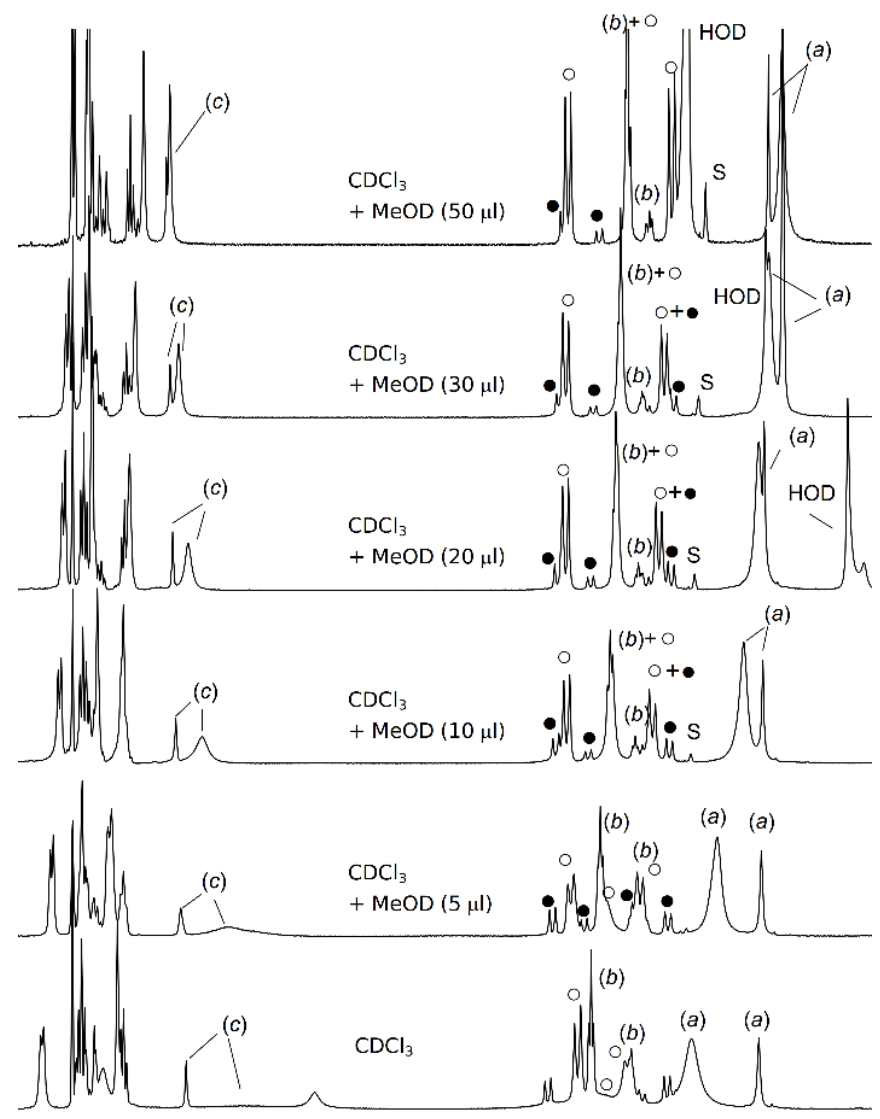

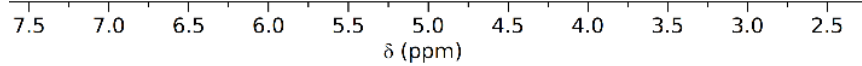

Figure 5. NMR stack plot (400 MHz, expanded region, see Fig. S17, Si, for full range) recorded upon addition of increasing amount of $\mathrm{CD}_{3} \mathrm{OD}$ to a solution of DPU in $\mathrm{CDCl}_{3}$ at $T=300 \mathrm{~K}$. The most significant resonances affected by methanol addition have been labelled according to Figure 3 . 
It thus seems that upon methanol addition, the protons of groups (a) and (b) experience a more shielding effect exerted by the aromatic units of DPU. On the other hand, the very broad and barely recognisable aromatic resonance at ca. $6.4 \mathrm{ppm}(c)$, becomes sharper with an augment of the methanol additions and almost merge with the sharp resonance at $6.7 \mathrm{ppm}$ which was previously ascribed to the minor conformer. The methanol addition also seems to affect the abundance of the two conformers with a shift in favour of the major conformer $\boldsymbol{A}-\mathbf{1}$ (from $4: 1$ to $5: 1$ ). This result could be tentatively explained supposing the flattened cone conformation is stabilised by an intramolecular $\mathrm{H}$-bonding between the two phenylurea moieties present on the macrocycle. Several 2D NMR experiments were successively accomplished on the sample with the highest amount of deuterated methanol added (50 $\left.\mu \mathrm{l}, \mathrm{CDCl}_{3} / \mathrm{CD}_{3} \mathrm{OD} 10 / 1\right)$. In particular, 2D COSY and HSQC experiments (see Fig. S18, SI) allowed us to unequivocally identify the three different signals relative to the bridging methylene protons - two doublets at 4.2 and $3.5 \mathrm{ppm}$ and a broad singlet at $3.8 \mathrm{ppm}$ - which are in full agreement with the structure of the 1,2,3-alternate conformer $(\boldsymbol{A}$ 1) illustrated in Figure 2.

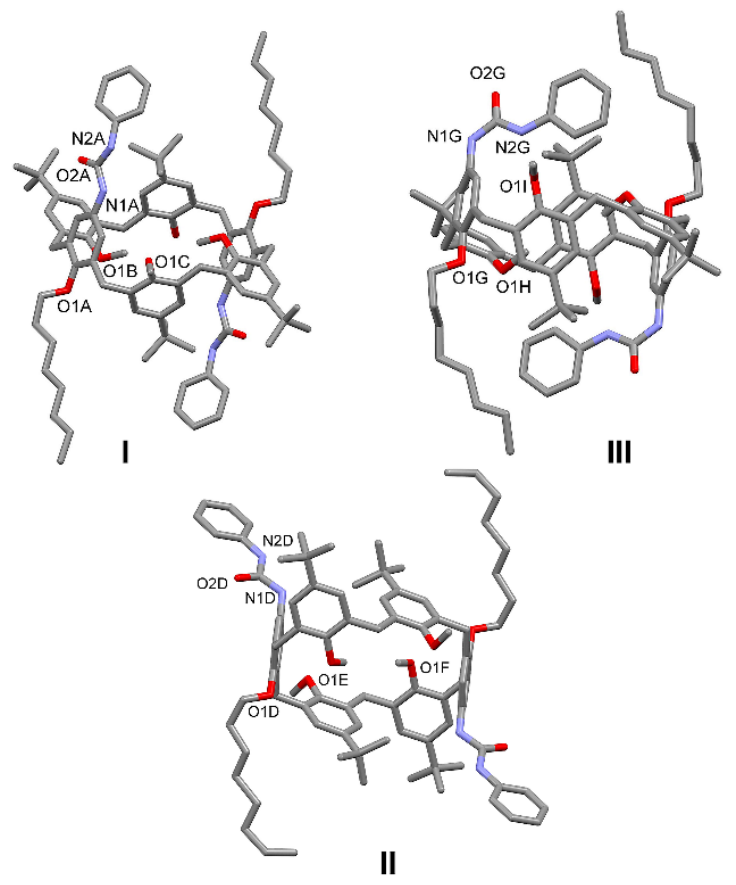

Figure 6. Molecular structure of I-III with partial labelling scheme for the atoms in the asymmetric unit. Hydrogen atoms and solvent molecules have been omitted for clarity.

\section{Description of the crystal structures}

The crystal structure of compound DPU was determined via synchrotron $\mathrm{X}$-ray diffraction data on single crystals obtained by slow evaporation of a $\mathrm{CHCl}_{3} / \mathrm{CH}_{3} \mathrm{OH}$ solution. In the unit cell, three different molecules co-exist, indicated in the discussion as I, II and III (see Figure 6). For each calix[6]arene of general formula $\mathrm{C}_{92} \mathrm{H}_{120} \mathrm{~N}_{4} \mathrm{O}_{8}, 2 / 3$ molecules of $\mathrm{CHCl}_{3}, 4 / 3$ molecules of $\mathrm{CH}_{3} \mathrm{OH}$.and $10 / 3$ molecules of $\mathrm{H}_{2} \mathrm{O}$ are present in the unit cell. For all the three macrocycles only half of the molecule is independent, while the other half is generated by symmetry [symmetry codes: (i) 1-x, 1-y, 2-z; (ii) = 1-x, 1-y, 1-z and (iii) = -x, y, 1-z for I, II and III, respectively]. The three independent aromatic rings forming the walls are labelled A, B, C (I), D, E, F (II) and G, H, I (III); the conformation of the cavity is always 1,2,3-alternate. The molecular structures I-III assume a geometry compatible with the 1,2,3-alternate conformation indicated in the previous discussion as $\boldsymbol{A - 2}$ (cf. Figures 2 and 6 ). With respect to the mean plane passing through the six methylene bridges, the mean planes passing through the aromatic rings are inclined of 67.4(2), 36.8(3), 63.4(2), 74.3(4), 62.7(3), 40.7(3), 79.1(2), 44.2(2) and 68.8(3) ${ }^{\circ}$ for A, B, C (I), D, E, F (II), G, H and I (III) (the values reported are always those smaller than $90^{\circ}$ ). In III, the phenylureido moiety is not parallel to the aromatic walls of the macrocycle like in I and II, but it is inclined towards the cavity as evidenced by the torsion angles C4-N1-C16-N2 [C4A-N1A-C16A-N2A = 176.6(3) ${ }^{\circ}$ (I); C4D-N1D-C16D-N2D = -161.5(3) ${ }^{\circ}$ (II); C4G-N1G-C16G-N2G = $9.2(4)^{\circ}$ (III)]. These findings confirmed the results previously obtained in the variable temperature NMR experiment (see Figure 4).
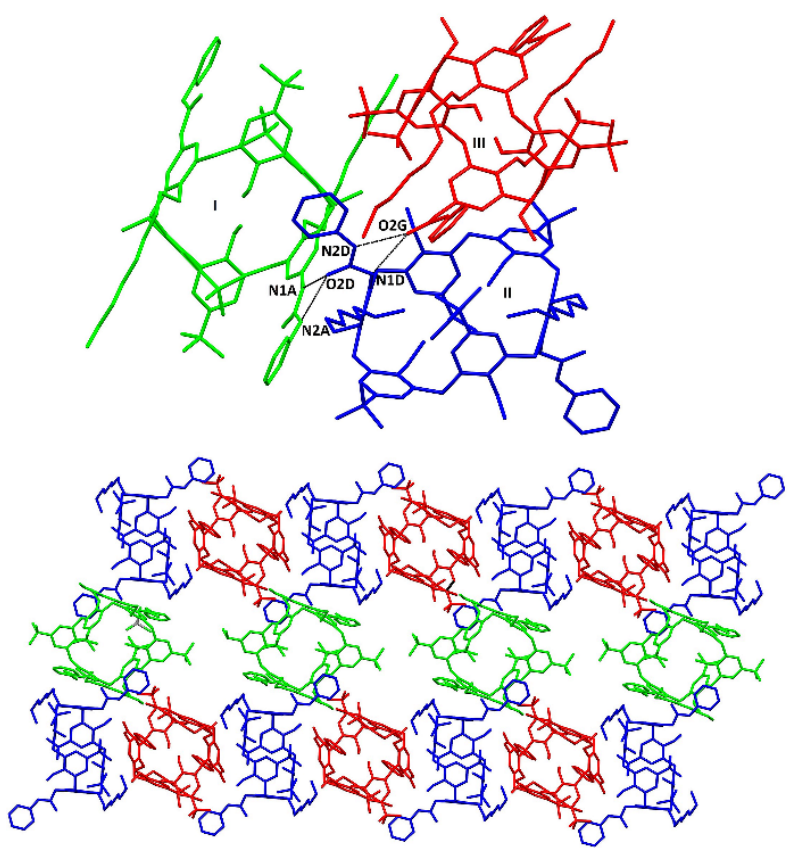

Figure 7. (top) The set of $\mathrm{H}$ bonds involving the three independent molecules I, II and III, with partial labelling scheme. Hydrogen atoms and solvent molecules have been omitted for clarity. $\mathrm{H}$ bonds are shown as black lines; (down) view of the supramolecular sheet formed by I (green), II (blue) and III (red) macrocycles. Hydrogen atoms and solvent molecules have been omitted for clarity.

In each calixarene, two methoxy groups point inside the cavity, namely O1B-C8B (I), O1F-C8F (II), O1H-C8H (III) and their symmetry-related equivalents, forming $\mathrm{C}-\mathrm{H} \cdots \pi$ interactions with the aromatic walls which stabilize the $\boldsymbol{A - 2}$ conformer [C8B-

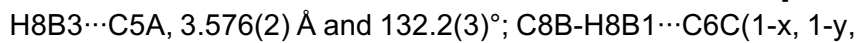
2-z), 3.407(4) $\AA$ and $126.9(5)^{\circ} ; \mathrm{C} 8 \mathrm{~F}-\mathrm{H} 8 \mathrm{~F} 1 \cdots \mathrm{C} 2 \mathrm{E}, 3.451(3) \AA$ and 128.0(5) $)^{\circ} ; \quad \mathrm{C} 8 \mathrm{~F}-\mathrm{H} 8 \mathrm{~F} 3 \cdots \mathrm{C} 5 \mathrm{D}(1-\mathrm{x}, 1-\mathrm{y}, 1-\mathrm{z}), \quad 3.759(3) \quad \AA \quad$ and $133.8(4)^{\circ} ; \mathrm{C} 8 \mathrm{H}-\mathrm{H} 8 \mathrm{H} 3 \cdots \mathrm{C} g 1,3.779(1) \AA$ and $157.9(3)^{\circ} ; \mathrm{C} 8 \mathrm{H}-$ $\mathrm{H} 8 \mathrm{H} 2 \cdots \mathrm{C} 2 \mathrm{I}(-\mathrm{x},-\mathrm{y}, 1-\mathrm{z}), \quad 3.526(5) \quad \AA \quad$ and $143.8(3)^{\circ} ; \quad \mathrm{C} 8 \mathrm{H}-$ $\mathrm{H} 8 \mathrm{H} 2 \cdots \mathrm{C} 3 \mathrm{I}(-\mathrm{x},-\mathrm{y}, 1-\mathrm{z}), 3.725(4) \AA$ and $145.3(3)^{\circ}$. C6C, C2E, C5D $\mathrm{C} 2 \mathrm{I}$ and $\mathrm{C} 3 \mathrm{I}$ belongs to the rings $\mathrm{C} 1 \mathrm{~A}-\mathrm{C} 6 \mathrm{~A}, \mathrm{C} 1 \mathrm{C}-\mathrm{C} 6 \mathrm{C}, \mathrm{C} 1 \mathrm{E}-\mathrm{C} 6 \mathrm{E}$, C1D-C6D and C1I-C6I, respectively. $\mathrm{Cg} 1$ is the centroid of the 
benzene ring $\mathrm{C} 1 \mathrm{G}-\mathrm{C} 6 \mathrm{G}]$. In the lattice, the three molecules are connected through $\mathrm{H}$ bonds involving the ureido groups, with the $\mathrm{N}-\mathrm{H}$ atoms behaving as donors and the oxygen atoms as acceptors [see Figure 7; N1A-H1A $\cdots \mathrm{O} 2 \mathrm{D}, 2.891(3) \AA$ and 161.4(2) $;$ N2A-H2A $\cdots \mathrm{O} 2 \mathrm{D}, 2.916(3) \AA$ and $14.46(2)^{\circ} ; \mathrm{N} 1 \mathrm{D}-$ H1D $\cdots \mathrm{O} 2 \mathrm{G}, 2.820(3) \AA$ and $129.3(2)^{\circ}$; N2D-H2D $\cdots \mathrm{O} 2 \mathrm{G}, 2.933(3)$ $\AA$ and $\left.140.2(2)^{\circ}\right]$. The overall crystal packing results in a supramolecular sheet formed by the three independent molecules I (green), II (blue) and III (red). The sheet is parallel to the (1-10) plane and consists of alternating adjacent chains following the pattern $A B A B$, where the chain $A$ is formed by $H$-bonded calixarenes II and III, while chains B comprise calixarenes I, Hbonded to water, methanol and chloroform molecules (not shown in the figure). In order to investigate the influence of the solvent on the crystal structure, calix[6]arene DPU was crystallised from ethyl acetate, yielding the monosolvate form IV, whose molecular structure can be seen in Fig S19 of the SI. The asymmetric unit, crystallising in the monoclinic space group $C 2 / c$, comprises half of a molecule of the macrocycle and of ethyl acetate. With respect to the mean plane passing through the six methylene bridges, the mean planes passing through the aromatic rings are inclined of 69.5(2), 45.3(3) and 68.8(3) ${ }^{\circ}$ for rings A, B and C, respectively (in good agreement with the values found for I, II and III; the same labelling scheme has been used). The torsion angle C4A-N1AC16A-N2A (which characterises the position of the phenylureido moiety with respect to the aromatic walls) is $-177.8(3)^{\circ}$, similar to forms I and II. Also in this case, the methoxy group O1B-C8B and its symmetry-related equivalent point inside the cavity, forming $C$ $\mathrm{H} \cdots \pi$ interactions with the aromatic rings $\mathrm{C} 1 \mathrm{~A}-\mathrm{C} 6 \mathrm{~A}$ and $\mathrm{C} 1 \mathrm{C}-\mathrm{C} 6 \mathrm{C}$

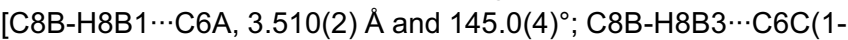
$\mathrm{x}, 1-\mathrm{y}, 1-\mathrm{z}), \quad 3.326(3) \quad \AA$ and $\left.128.0(3)^{\circ}\right]$, stabilizing the $\boldsymbol{A}-2$ conformer. The main supramolecular feature in IV is the presence of two strong $\mathrm{H}$-bonds between the $\mathrm{N}-\mathrm{H}$ groups of the phenylureido moiety and the oxygen atom 01 of the acetate solvent [N1A-H1A $\cdots \mathrm{O} 1,2.960(6) \AA$ and $155.3(2)^{\circ}$; N2A-H2A $\cdots 01$, $2.904(5) \AA$ and $\left.153.5(5)^{\circ}\right]$. These strong interactions are also present in the crystal structure of the three independent calixarenes I, II and III, but in that case, the H-bond acceptors are the oxygen atoms of the phenylureido unit of adjacent calixarenes, thus also influencing the packing of the compound. In IV, the overall crystal structure is mainly driven by van der Waals interactions, yielding layers parallel to the $a b$ plane (see Figure S19, SI)

Synthesis and characterisation of the intervowen structures The ability of DPU to form pseudorotaxanes complexes with viologen salts was initially tested in $\mathrm{CDCl}_{3}$ solution using 1,1'dioctyl-4,4'-bipyridinium di-tosylate ( $\mathbf{D O V} \times 2 \mathrm{TsO}$ ) as the axle (see Scheme 2). Like TPU, ${ }^{[8]}$ also DPU is capable of dissolving this unsoluble viologen salt giving rise to a red-coloured homogeneous solution. The NMR spectrum of the solution shows a very complicated pattern of signals (see Figure $8 \mathrm{~b}$ and Fig. S23, $\mathrm{SI})$. However, with respect to the free DPU, it is possible to observe the presence of two broad signals in the upfield region of the spectrum ( 0.3 and $0.4 \mathrm{ppm})$. With the aid of 2D TOCSY and HSQC experiments (see Fig. S25-26, SI), these signals were assigned to the methylene groups of the DOV octyl chains labelled as $(\&)$ and $(\S)$ in Scheme 2. As seen for TPU, ${ }^{[12-14]}$ the appearance of these methylene resonances is usually ascribed to the formation of a pseudorotaxanes complex.
Scheme 2. Synthesis of the Rotaxane 4

Differently from what generally observed with TPU, the HSQC spectrum revealed that with DPU the DOV methylene groups linked to the pyridinium rings (\#) (see Scheme 2) give rise to three signals at 3.6, 3.3 and $2.3 \mathrm{ppm}$, in 0.6:1:0.6 integration ratio (integration accomplished on the HSQC correlations, see Fig. $\mathrm{S} 26, \mathrm{SI})$, instead of the usual two. Although all three upfieldshifted with respect to the chemical shift of the free DOV (4.6 ppm), their number suggests the formation of more than one pseudorotaxane complex, each of them characterised by a different geometrical arrangement of the calix[6]arene wheel around the viologen axle. We know that, at room temperature and in chloroform solution, the DPU wheel assumes both the "symmetric" cone and the "asymmetric" 1,2,3-alternate conformation Therefore, we deduced that the signals with same intensity at 3.6 and $2.3 \mathrm{ppm}$ are associated to the octyl chains of a thread buried in asymmetric magnetic environment, such as the one present in a pseudorotaxanes complex in which the calix[6]arene macrocycle adopts a flattened cone conformation (see Scheme 2). Indeed, the multiple correlations of the TOCSY spectrum (see Fig. S25, SI), which start from the most upfieldshifted of these two signals (\#'), allowed us to identify the thread octyl chain oriented toward the calix[6]arene upper rim and accounting for the most-shielded signals at $0.3\left(\S^{\prime}\right)$ and $0.4\left(\&^{\prime}\right)$ $\mathrm{ppm}$. From the resonances at $3.6 \mathrm{ppm}(\# ")$ departs another series of TOCSY correlations identifying the octyl chain of the thread protruding from the cavity, which experiences a lesser shielding effect. The signals of the methylene group at $3.3 \mathrm{ppm}$ (\#"') was thus assigned to the octyl chains of a thread enwrapped by a calix[6]arene in the 1,2,3-alternate conformation. The above findings were confirmed also by the observation that in these conditions, the DPU wheel yields three resonances for the methoxy groups at $4.1\left(a^{\prime}\right), 4.0\left(a^{\prime \prime \prime}\right)$ and $3.8\left(a^{\prime \prime}\right)$ ppm, and three for its $\mathrm{OCH}_{2}$ at $3.8\left(b^{\prime}\right), 3.7\left(b^{\prime \prime \prime}\right)$ and $3.6\left(b^{\prime \prime}\right)$ ppm (the last two overlapped, see HSQC, Fig. S26, SI). The ROESY spectrum (see Fig. S27, SI) presents weak correlations between the resonances of the methylene groups (\#) and those of the ortho aromatic protons $(£)$ of the pyridine rings. The resonance at $2.3 \mathrm{ppm}\left(\#^{\prime}\right)$ is spatially correlated with a resonance at $7.28 \mathrm{ppm}\left(£^{\prime}\right)$, hidden by the residual solvent signal, while that at $3.6 \mathrm{ppm}(\# ")$ with a small 
and broad aromatic signal at $8.3 \mathrm{ppm}\left(£^{\prime \prime}\right)$. The HSQC spectrum confirmed that these aromatic resonances correspond to the ortho protons of the pyridinium rings (see Fig. S26, SI). Through the TOCSY (see Fig. S24, SI), these signals were used to assign those of the other pyridinium protons (meta) at 8.5 and $7.5 \mathrm{ppm}$, which are indicated as (\$) and (\$") in Scheme 2. Following a similar approach, it was possible to link the signal of the methylene group at $3.3 \mathrm{ppm}\left(\#^{\prime \prime \prime}\right)$ to the pyridinium aromatic signals at $7.2\left(£^{\prime \prime \prime}\right)$ and $7.6\left(\$^{\prime \prime \prime}\right)$ ppm. Differently from the free wheel, in this mixture of pseudorotaxanes, the ratio between the 1,2,3-alternate and the cone conformation changes from $4: 1$ to 1.2:1. This shift in favour of the cone conformation can be explained considering that in low polarity solvents DOV is present as a tight ion pair that, to allow the threading of the dication inside the aromatic cavity, must be separated. This process will likely be more favoured for the cone conformer since it has the urea moieties on the same side of the macrocycle (vide infra).

For the synthesis of the rotaxane 4 , we used the 1,1'-bis(12hydroxydodecyl)-4,4'-bipyridinium ditosylate (DDOV $\times 2 \mathrm{TsO})$ as the axle. Indeed, upon complexation, this thread might promote the rotaxanation reaction by the insertion of bulky diphenylacetyl chloride groups on its hydroxyl termini. Following a procedure verified in previous studies, ${ }^{[10,12,14]}$ the solid $\mathrm{DDOV} \times 2 \mathrm{TsO}$ was mixed with a solution of DPU in $\mathrm{CH}_{2} \mathrm{Cl}_{2}$ to promote the formation of pseudorotaxanes (DPU $\supset$ DDOV). After 12 hours of mixing at room temperature, the undissolved salt was eliminated by filtration and the resulting homogeneous solution treated with diphenylacetyl chloride to complete the stoppering reaction (see Scheme 2). In this way, rotaxanes 4 was isolated in $48 \%$ yield after chromatographic separation. As verified by ${ }^{1} \mathrm{H}$ NMR measurements, the low conversion was explained considering that the formation of the pseudorotaxanes (DPU $D D D O V)$ at room temperature was not complete (see stack plot of Fig. S27, SI). Nevertheless, HR-MS (TOF) measurements confirmed the identity of the isolated rotaxane (see Fig. S28, SI). The ${ }^{1} \mathrm{H}$ NMR spectrum in $\mathrm{CDCl}_{3}$ of 4 (see Fig. S27, SI) shows several common features with that of pseudorotaxanes DPU $\supset$ DOV and DPU $\triangle D D O V$. In particular, the presence of two broad signals in the upfield $(0.1-0.5 \mathrm{ppm})$ region of the spectrum, which are indicative of the formation of the interwoven structure. As verified for pseudorotaxane DPU $\triangle$ DOV, also in this case the pattern of the three signals for both the methoxy (a) and the octyl $\mathrm{OCH}_{2}$ methylene $(b)$ groups, are consistent for the presence of a mixture of rotaxanes in which the calix[6]arene adopt the cone and 1,2,3alternate conformation when wrapped around the viologen thread. This hypothesis was verified by the analysis of a series of $1 \mathrm{D}$ and 2D NMR spectra (see Fig. 29-33, SI).

\section{UV-Vis Characterization}

The interwoven structures were characterized by UV-Vis spectroscopy. The absorption spectrum of DPU is characterized by an intense band in the UV, with $\lambda_{\max }=260 \mathrm{~nm}$ and $\varepsilon=38000$ $\mathrm{M}^{-1} \mathrm{~cm}^{-1}$. This band is red shifted and less intense with respect to the parent calixarene bearing three phenylureido moieties (TPU) ${ }^{[9]}$ These differences can be ascribed to the lack of one chromophoric unit, but also to the different conformations assumed by the molecule in solution.

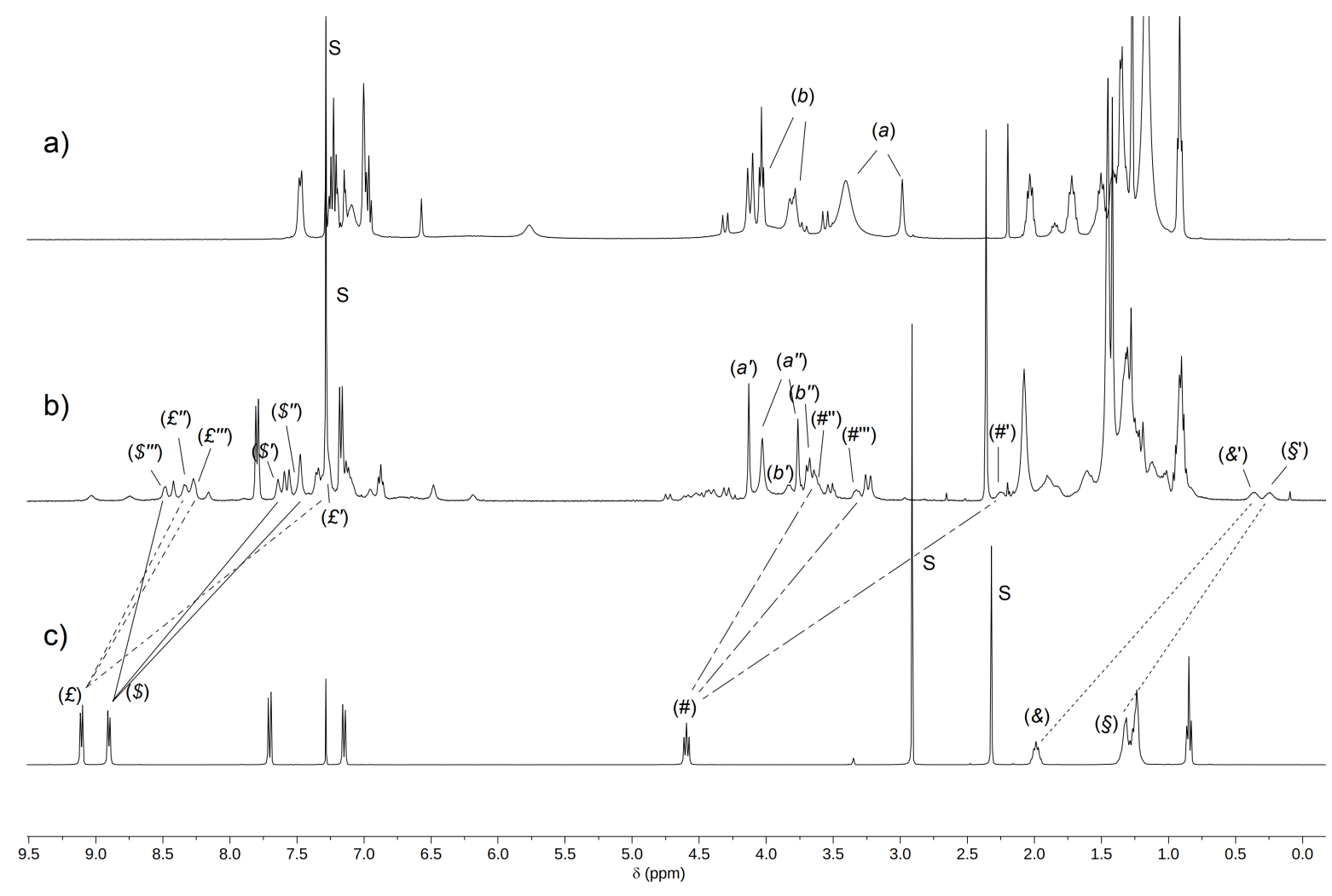

Figure 8. ${ }^{1} \mathrm{H}$ NMR stack plot ( $400 \mathrm{MHz}$ ) of a) $\mathbf{D P U}$, b) pseudorotaxanes $\mathbf{D P U} \supset \mathbf{D O V}$ in $\mathrm{CDCl}_{3}$ and c) $\mathbf{D O V} \times 2 \mathrm{TsO}$ in $\mathrm{CDCl}_{3} / \mathrm{CD}_{3} \mathrm{OD}=10 / 1$. For the labels see text and Scheme 2 . 
Upon titration of a solution of DOV with DPU, the solution turns red and a characteristic charge-transfer band appears, with a maximum around $500 \mathrm{~nm}$. This band was observed also in related pseudorotaxanes based on TPU calixarenes, and it is ascribed to the charge transfer interaction between the bipyridinium unit and the aromatic rings of DPU (Figure 9). The association constant determined by fitting the data with a 1:1 binding model is $3.2 \times 10^{6} \mathrm{M}^{-1}$. Indeed, the results of the thermodynamic investigation would suggest that the number of phenylurea moieties does not affect the stability of the pseudorotaxane. The corresponding rotaxane 4 was characterized by UV-Vis spectroscopy, and, as expected, it displays the same features of the pseudorotaxane: an intense band in the UV and a weak and broad band in the visible region of the spectrum. In line with the observations reported on the DPU ring component, the absorption coefficient at $\lambda_{\max }$ is lower with respect to the parent rotaxanes bearing a TPU macrocycle. ${ }^{[10,14]}$

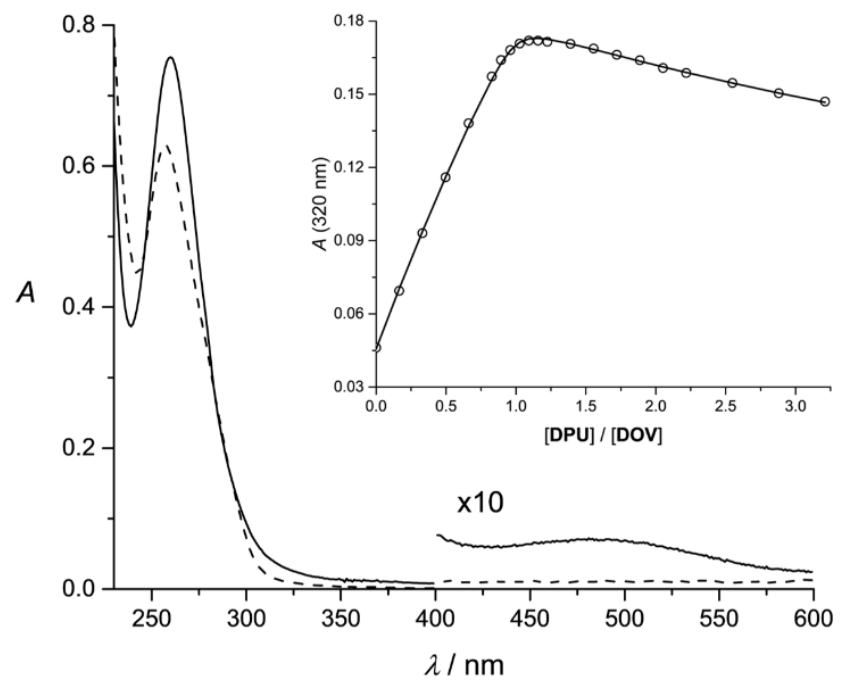

Figure 9. Sum of the absorption spectra (dashed line) and absorption spectrum of the mixture (straight line) of $\mathrm{CH}_{2} \mathrm{Cl}_{2}$ solutions of DOV $\left(1.4 \times 10^{-5} \mathrm{M}\right)$ and DPU $\left(1.2 \times 10^{-5} \mathrm{M}\right)$. The inset shows the absorption changes at $320 \mathrm{~nm}$ together with the fitted curve upon titration of a $7.4 \times 10^{-5} \mathrm{M}$ solution of DOV with concentrated DPU.

In order to investigate the dynamics of the threading process, kinetic experiments were performed by means of a stopped-flow apparatus. DPU and DOV were mixed in equimolar amounts and the absorption changes were followed in the UV and visible regions (Figure 9 and Figure 10). The kinetic traces were fitted with an equilibrium model, by fixing the equilibrium constant to the value determined upon titration. The rate constants for threading and dethreading resulted to be, respectively, $3.4 \times 10^{3} \mathrm{M}^{-1} \mathrm{~s}^{-1}$ and $1.1 \times 10^{-3} \mathrm{~s}^{-1}$. These values are three orders of magnitude lower with respect to the parent pseudorotaxane with TPU. ${ }^{[9,16]}$ As a matter of fact, phenylurea moieties are good anion receptors, ${ }^{[23,24]}$ and it is well known that in this kind of systems they play a crucial role in driving the formation of the supramolecular adduct. In particular, it has been hypothesized the involvement of a transition state wherein the counterions are no more paired with the bipyridinium unit, but they are already engaged with the calixarene. ${ }^{[9]}$ The present results would support this hypothesis, confirming the role of the phenylurea units in the stabilization of this transition state. As the electrochemical experiments were performed in presence of a 100-fold excess of tetrabutylammonium hexafluorophosphate $\left(\mathrm{TBAPF}_{6}\right)$ as the supporting electrolyte (vide infra), thermodynamic investigations were also performed in these experimental conditions. Indeed, the shape of the titration curve (Figure S34, SI) suggests a lower association, and the value of the stability constant determined by fitting the data with a $1: 1$ binding model is $7 \times 10^{4} \mathrm{M}^{-1}$. An effect of the concentration and of the nature of the anions on the stability of the supramolecular complex is not unexpected, considering the double role played by the counterions in the formation and stabilization of the pseudorotaxane: $:^{[9]}$ not only the phenylurea moieties are good anion receptors, as mentioned above, but also the formation of the pseudorotaxane is in competition with the ionpairing between the bipyridinium ion and its counteranions. ${ }^{[25,26]}$

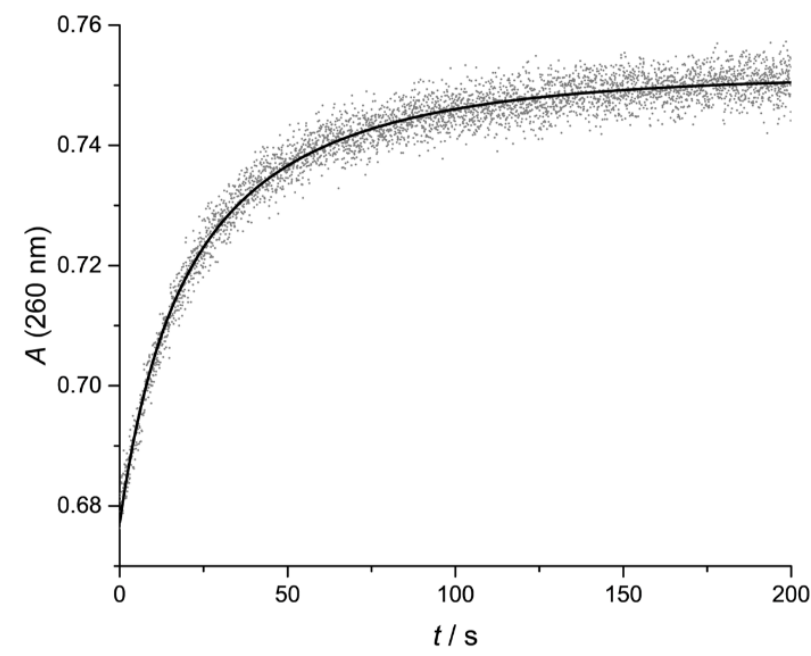

Figure 10. Absorption changes at $260 \mathrm{~nm}$ upon rapid mixing of equimolar amounts of DOV and DPU. The concentration of the reactants after mixing was $1.3 \times 10^{-5} \mathrm{M}$.

\section{Electrochemical experiments}

Cyclic voltammetry and differential pulse voltammetry experiments were performed on the pseudorotaxane and rotaxane molecules, in $\mathrm{CH}_{2} \mathrm{Cl}_{2}$, in presence of a 100 -fold excess of $\mathrm{TBAPF}_{6}$ as supporting electrolyte. The bipyridinium moiety of DOV is characterized by two reversible and monoelectronic reduction processes, at $E_{1 / 2}^{\prime}=-0.27 \mathrm{~V}$ and $E_{1 / 2}{ }^{\prime \prime}=-0.83 \mathrm{~V}$. When the viologen is included in the cavity of a calix[6]arene macrocycle, the reduction processes are shifted to more negative potential values, on account of the host-guest electron transfer interactions (Figure 11). ${ }^{[10,14]}$ Indeed, the cyclic voltammetric curves of rotaxane $\mathbf{4}$ are characterized by two quasi-reversible waves, with $E_{1 / 2}^{\prime}=-0.65 \vee$ and $E_{1 / 2}^{\prime \prime}=-1.18 \mathrm{~V}$. As observed for related TPUbased rotaxanes, ${ }^{[9]}$ these processes are clearly affected by slow heterogeneous electron-transfer kinetics. The pseudorotaxane obtained by mixing DPU and DOV in equimolar amounts shows the typical cyclic voltammetry curves described by an electrochemical process followed by a chemical reaction (EC square scheme) (Figure 11).$^{[9,27,28]}$ A fraction of free DOV is still present in solution, as evidenced by the small cathodic process 
around $-0.3 \mathrm{~V}$. This is not unexpected on the basis of the association constant determined in presence of an excess of $\mathrm{PF}_{6}$ ions and of the effect of the ion pair dissociation on the formation of the complex. ${ }^{[25,26]}$ Indeed the intensity of this signal decreases on increasing the concentration of DPU. On the other hand, the encapsulated DOV is reduced at more negative potential values, but, after the first reduction, the complex dissociates and the second reduction process of free DOV is displayed at $-0.82 \mathrm{~V}$. Upon re-oxidation, only the processes of free DOV are observed: as a matter of fact, the first reduction process is characterized by a large separation between the cathodic and anodic peaks. This pattern can be modelled with an EC square scheme mechanism, and is indicative of slow kinetics of the monoreduced bypiridinium..$^{[9,27,28]}$ Therefore, in analogy with parent TPU-based systems, pseudorotaxanes based on the DPU wheel can be disassembled by electrochemical reduction of the bipyridinium axle. Indeed the results of the electrochemical investigation suggest that the two different conformers behave in a similar way and the 1,2,3-alternate and the cone conformation assumed by the interlocked structure cannot be distinguished in our experimental conditions.

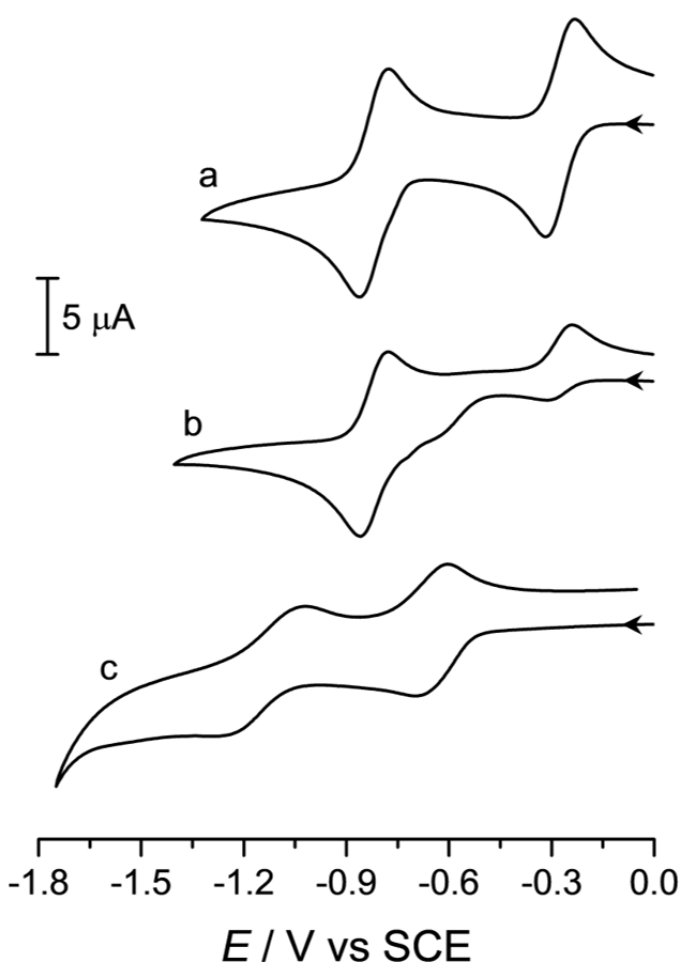

Figure 11. Cyclic voltammetric curves for the first and second reduction of the bipyridinium unit in (a) DOV (c=3.0 x 10 M), (b) DPU $\triangle$ DOV $\left(c=3.0 \times 10^{-4} \mathrm{M}\right)$, and (c) $4\left(\mathrm{c}=1.1 \times 10^{-4} \mathrm{M}\right)\left(\mathrm{CH}_{2} \mathrm{Cl}_{2}, 100\right.$-fold $\mathrm{TBAPF}_{6}$, scan rate $\left.100 \mathrm{mV} / \mathrm{s}\right)$.

\section{Conclusions}

A new calix[6]arene-based host (DPU) functionalised with two phenylurea moieties in 1,4-diametral position was synthesised and structurally characterised. Detailed NMR studies evidenced that in solution of low polarity solvents this host mainly adopts a 1,2,3-alternate conformation. The determination of the crystal structure via X-ray diffraction on single crystals showed that DPU assumes this conformation also in the solid state. The ability of DPU to act as a wheel for the formation of pseudorotaxane and rotaxane species with viologen-based salts was investigated in solution of low polarity solvents through NMR, UV-vis and electrochemical measurements. The NMR studies evidenced that the formation of interwoven structures occurs with the host adopting both the cone and 1,2,3-alternate conformation. Kinetic experiments showed that the rate constants for threading and dethreading of the viologen salts are three orders of magnitude lower with respect to the parent pseudorotaxane with TPU that, in low polarity solvents, is in the cone conformation. These findings thus account for the crucial role played by the number, orientation and reciprocal arrangement of the phenylurea binding groups in promoting the thread of the dicationic portion of the ion pair viologen salts. The ability of DPU to exploit its particular 1,2,3alternate conformation and self-assemble to yield polyrotaxane structures is currently undergoing in our laboratories.

\section{Experimental Section}

\section{Synthesis and characterisation}

Solvents were dried following standard procedures; all other reagents were of reagent grade quality, obtained from commercial sources and used without further purification. Chemical shifts are expressed in ppm using the residual solvent signal as an internal reference. Mass spectra were determined in ESI mode. Calix[6]arene $1,{ }^{[21]}$ axles $\mathbf{D O V} \times 2 \mathrm{TsO}^{[9]}$ and $\mathrm{DHDOV} \times 2 \mathrm{TsO}^{[8,10]}$ were synthesised according to reported procedures.

Calix[6]arene 2: In a $100 \mathrm{~mL}$ Schlenk flask, to a solution of calixarene 1 $(1 \mathrm{~g}, 1 \mathrm{mmol})$ and 1-lodooctane $(0.72 \mathrm{~g}, 3 \mathrm{mmol})$ in dry acetonitrile $(50 \mathrm{~mL})$, $\mathrm{K}_{2} \mathrm{CO}_{3}(0.41 \mathrm{~g}, 3 \mathrm{mmol})$ was added. After two vacuum/nitrogen cycles, the flask was sealed and the heterogeneous reaction mixture was refluxed for 4 days. After cooling to room temperature, the solvent was evaporated to dryness under reduced pressure, and the sticky residue was taken up with dichloromethane $(50 \mathrm{~mL})$ and with a $10 \%$ aqueous solution of $\mathrm{HCl}(30 \mathrm{~mL})$. The separated organic phase was washed thrice with distilled water, dried over anhydrous $\mathrm{Na}_{2} \mathrm{SO}_{4}$, filtered and evaporated to dryness under reduced pressure. The solid residue was triturated with hot ethyl acetate to give, after Buchner filtration, $0.85 \mathrm{~g}$ of pure $2(70 \%$ yield) as a white solid compound. $\mathrm{Mp}>300{ }^{\circ} \mathrm{C}$; ${ }^{1} \mathrm{H}$ NMR $\left(400 \mathrm{MHz}, \mathrm{CDCl}_{3}\right): \delta=0.90\left(\mathrm{t}, 6 \mathrm{H},{ }^{3} \mathrm{~J}_{\mathrm{H}, \mathrm{H}}\right.$ $\left.=8 \mathrm{~Hz},-\mathrm{OCH}_{2} \mathrm{CH}_{2}\left(\mathrm{CH}_{2}\right)_{5} \mathrm{CH}_{3}\right), 1.22,1.3-1.5$ and $1.6\left(\mathrm{~s}, \mathrm{~m}, \mathrm{br} . \mathrm{s}, 56 \mathrm{H},{ }^{\mathrm{t}} \mathrm{Bu}\right.$ and $-\mathrm{OCH}_{2} \mathrm{CH}_{2}\left(\mathrm{CH}_{2}\right)_{5} \mathrm{CH}_{3}$ ), 1.9 (br. s, $4 \mathrm{H},-\mathrm{OCH}_{2} \mathrm{CH}_{2}\left(\mathrm{CH}_{2}\right)_{5} \mathrm{CH}_{3}$ ), 3.0 (br. s, $12 \mathrm{H}, \mathrm{ArOCH}_{3}$ ), 3.6 (br. d, $4 \mathrm{H}, \mathrm{Ar}-\mathrm{CH}_{2}-\mathrm{Ar}$ (equatorial)), 3.92 (br. s, $8 \mathrm{H}$, $-\mathrm{OCH}_{2} \mathrm{CH}_{2}\left(\mathrm{CH}_{2}\right)_{5} \mathrm{CH}_{3}$ and $\mathrm{Ar}-\mathrm{CH}_{2}-\mathrm{Ar}$ ), 4.3 (br. d, $4 \mathrm{H}, \mathrm{Ar}-\mathrm{CH}_{2}-\mathrm{Ar}$ (axial)), 6.96 (s, $4 \mathrm{H}, \mathrm{Ar}-\mathrm{H}$ ), 7.22 (br. s, $4 \mathrm{H}, \mathrm{Ar}-\mathrm{H}$ ), 7.64 (br. s, $4 \mathrm{H}, \mathrm{Ar}-\mathrm{H}$ ); ${ }^{13} \mathrm{C}$ NMR $\left(100 \mathrm{MHz}, \mathrm{CDCl}_{3}\right): \delta=14.0,22.6,26.2,29.2,29.5,30.4,30.7,30.8,31.3$, $31.8,34.2,59.7,74.0,123.0,126.4,126.9,132.1,133.9,136.5,143.5$, 146.4, 154.1, 160.0 ppm; Elemental Analysis calcd. for $\mathrm{C}_{78} \mathrm{H}_{106} \mathrm{~N}_{2} \mathrm{O}_{10}: \mathrm{C}$, 76.06; H, 8.67; N, 2.27; found: C, 76.5; H, 8.88; N, 1,93; ESI-MS(+): m/z $(\%)=1253.9(100)[\mathrm{M}+\mathrm{Na}]^{+}, 1254.9(70)[\mathrm{M}+\mathrm{Na}+1]^{+}, 1269.9(70)[\mathrm{M}+\mathrm{K}]^{+}$, $1270.9(60)[\mathrm{M}+\mathrm{K}+1]^{+}$.

Bis(N-phenylureido)calix[6]arene DPU: In a two-neck flask kept under inert atmosphere, to a solution of $2(0.7 \mathrm{~g}, 0.57 \mathrm{mmol})$ in ethanol $(150 \mathrm{~mL})$, hydrazine monohydrate $(1.42 \mathrm{~g}, 28 \mathrm{mmol})$ and a tip of spatula of $10 \% \mathrm{Pd} / \mathrm{C}$ catalyst were added. The resulting mixture was refluxed for $48 \mathrm{~h}$ and then filtered, still warm and under an inert atmosphere, through a celite pad to remove the palladium catalyst. The filtered solution was evaporated to dryness under reduced pressure. The residue was taken up in dichloromethane $(50 \mathrm{~mL})$, and the resulting organic phase was washed thrice with water to remove the excess of hydrazine. The separated 
organic phase was dried over anhydrous $\mathrm{CaCl}_{2}$, filtered and evaporated to dryness under reduced pressure. The residue was dissolved in anhydrous dichloromethane $(50 \mathrm{~mL})$ and placed in a two-neck flask kept under an inert atmosphere. To the resulting homogeneous solution, pheny isocyanate $(0.17 \mathrm{~g}, 1.4 \mathrm{mmol})$ was added. The reaction mixture was stirred at room temperature for $24 \mathrm{~h}$; then the solvent was removed under reduced pressure. Purification of the residue by column chromatography (eluent $n$ hexane: ethyl acetate $75: 25$ ) afforded DPU in $80 \%$ yield as a white solid compound. Mp. $236-238{ }^{\circ} \mathrm{C} ;{ }^{1} \mathrm{H}$ NMR $\left(400 \mathrm{MHz}, \mathrm{CDCl}_{3} / \mathrm{CD}_{3} \mathrm{OD}=10 / 1\right)$ : $\delta=0.8\left(\mathrm{t}, 6 \mathrm{H},{ }^{3} \mathrm{~J}_{\mathrm{H}, \mathrm{H}}=8 \mathrm{~Hz},-\mathrm{OCH}_{2} \mathrm{CH}_{2}\left(\mathrm{CH}_{2}\right)_{5} \mathrm{CH}_{3}\right), 1.1\left(\mathrm{~s}, 36 \mathrm{H},{ }^{\mathrm{t}} \mathrm{Bu}\right), 1.2$ $1.3\left(\mathrm{~m}, 20 \mathrm{H},-\mathrm{OCH}_{2} \mathrm{CH}_{2}\left(\mathrm{CH}_{2}\right)_{5} \mathrm{CH}_{3}\right), 1.4-1.5\left(\mathrm{~m}, 4 \mathrm{H}, \mathrm{OCH}_{2} \mathrm{CH}_{2}\left(\mathrm{CH}_{2}\right)_{5} \mathrm{CH}_{3}\right)$, 1,7-1.8 (m, $\left.4 \mathrm{H},-\mathrm{OCH}_{2} \mathrm{CH}_{2}\left(\mathrm{CH}_{2}\right)_{5} \mathrm{CH}_{3}\right), 2.8$ (br. s, $\left.12 \mathrm{H}, \mathrm{ArOCH}_{3}\right), 3.5$ (br. d, $4 \mathrm{H}, \mathrm{Ar}-\mathrm{CH}_{2}-\mathrm{Ar}$ (equatorial)), 3.8 (br. S, $8 \mathrm{H},-\mathrm{OCH}_{2} \mathrm{CH}_{2}\left(\mathrm{CH}_{2}\right)_{5} \mathrm{CH}_{3}$ and Ar- $\mathrm{CH}_{2}$-Ar), 4.2 (br. d, $4 \mathrm{H}, \mathrm{Ar}-\mathrm{CH}_{2}-\mathrm{Ar}$ (axial)), 6.7 ( br. s, $4 \mathrm{H}, \mathrm{Ar}-\mathrm{H}$ ), 6.8 (br. s, $4 \mathrm{H}, \mathrm{Ar}-H), 6.9$ (m, $2 \mathrm{H}, \mathrm{Ar}-H$ ), 7.2 (br. s, $8 \mathrm{H}, \mathrm{Ar}-H$ ), 7.3 (br. s, $4 \mathrm{H}$, $\mathrm{Ar}-H) ;{ }^{13} \mathrm{C} \mathrm{NMR}\left(100 \mathrm{MHz}, \mathrm{CDCl}_{3} / \mathrm{CD}_{3} \mathrm{OD}=10 / 1\right): \delta=14.0,22.6,26.3$, 29.3, 29.6, 30.5, 31.2, 31.8, 34.1, 59.7, 60.2, 73.7, 119.0, 121.1, 122.5, $122.9,126.3,126.7,126.9,128.7,132.1,132.8,134.1,135.4,136.5,138.9$, $143.5,146.4,146.6,150.4,152.6,154.1 \mathrm{ppm} . \mathrm{HR}-\mathrm{MS}(+): \mathrm{m} / \mathrm{z}(\%)=$ 1409.9155 (9) $[\mathrm{M}+\mathrm{H}]^{+}, 1426.9436(100)\left[\mathrm{M}+\mathrm{NH}_{4}\right]^{+}, 1431.8998$ (45) $[\mathrm{M}+\mathrm{Na}]^{+}$.

Rotaxane 4: Calix[6]arene DPU $(0.05 \mathrm{~g}, 0.035 \mathrm{mmol})$ was dissolved in dry dichloromethane and 1,1'-bis(12-hydroxydodecyl)-4,4'-bipyridinium ditosylate DDOV $\times 2 \mathrm{TsO}(0.034 \mathrm{~g}, 0.039 \mathrm{mmol})$ was added. The solution was stirred at room temperature for 2 hours then diphenylacetylchloride $(0.021 \mathrm{~g}, 0.089 \mathrm{mmol})$ and triethylamine $(0.011 \mathrm{~g}, 0.11 \mathrm{mmol})$ were added. The reaction mixture was stirred at room temperature overnight. The solvent was evaporated under reduced pressure, and the crude product was purified by column chromatography (eluent: $\mathrm{CH}_{2} \mathrm{Cl}_{2} / \mathrm{MeOH}=92 / 2$ ). To assure the total exchange of the viologen counteranions as tosylates, the solid residue recovered from the chromatographic separation was dissolved in $25 \mathrm{~mL}$ of dichloromethane and the resulting organic phase was washed thrice with a saturated solution of sodium tosylate and twice with distilled water. After evaporation of the organic phase under reduced pressure, rotaxane 4 was isolated in $48 \%$ yield as a red solid compound. HR-MS (+): $\mathrm{m} / \mathrm{z}(\%)=1161.7550(78)[\mathrm{M}-2 \mathrm{TsO}]^{2+}$.

X-ray data collection and crystal structure determination: The crysta structures of the methanol/chloroform (I-III) and ethyl acetate (IV) solvates of DPU were determined by X-ray diffraction methods. Crystal data and experimental details for data collection and structure refinement are reported in Tables S1-S2 of the SI. Intensity data and cell parameters were recorded at 100(2) $\mathrm{K}$ at the ELETTRA Synchrotron Light Source (CNR Trieste, strada statale 14, Area Science Park, 34149, Basovizza, Trieste, Italy) for I-III, and at $150(2) \mathrm{K}$ on a Bruker D8 Venture Photonll diffractometer equipped with a CCD area detector, using a CuKa radiation $(\lambda=1.54178)$ for IV. The raw frame data were processed using the program package CrysAlisPro $1.171 .38 .41^{[29]}$ for I-III, and the programs SAINT and SADABS ${ }^{[30]}$ for IV. The structures were solved by Direct Methods using the SIR97 program ${ }^{[31]}$ and refined on $F_{0}^{2}$ by full-matrix least-squares procedures, using the SHELXL-2014/7 ${ }^{[32]}$ program in the WinGX suite v.2014.1. ${ }^{[33]}$ All non-hydrogen atoms were refined with anisotropic atomic displacements, except for some disordered alkyl chains or solvent molecules. The carbon-bound and the nitrogen-bound $\mathrm{H}$ atoms were placed in calculated positions and refined isotropically using a riding model with $\mathrm{C}-\mathrm{H}$ ranging from 0.93 to $0.97 \AA$ and $\operatorname{Uiso}(\mathrm{H})$ set to 1.2 $1.5 \mathrm{Ueq}(\mathrm{C}), \mathrm{N}-\mathrm{H}$ equal to 0.86 and $\mathrm{Uiso}(\mathrm{H})$ set to $1.2 \mathrm{Ueq}(\mathrm{N})$, and $\mathrm{O}-\mathrm{H}$ equal to 0.82 and $\mathrm{Uiso}(\mathrm{H})$ set to $1.5 \mathrm{Ueq}(\mathrm{O})$. The weighting schemes used in the last cycle of refinement were $w=1 /\left[\sigma^{2} F_{o}^{2}+(0.4534 P)^{2}\right]$ and $w=1 /\left[\sigma^{2} F_{o}^{2}\right.$ $\left.+(0.5768 P)^{2}\right]$ where $\mathrm{P}=\left(F_{o}^{2}+2 F_{c}^{2}\right) / 3$, for I-III and IV, respectively. Crystallographic data for the structures reported have been deposited with the Cambridge Crystallographic Data Centre as supplementary publication no. CCDC-1894692-1894693 and can be obtained free of charge on application to the CCDC, 12 Union Road, Cambridge, CB2 1EZ, UK (fax: +44-1223-336-033; e-mail deposit@ccdc.cam.ac.uk or http://www.ccdc.cam.ac.uk).

\section{UV-Vis absorption spectroscopy}

All spectroscopic measurements were performed on air-equilibrated $\mathrm{CH}_{2} \mathrm{Cl}_{2}$ (Uvasol) solutions at room temperature in $1 \mathrm{~cm}$ pathlength quartz cuvettes. UV-vis spectra were recorded with a Cary 300 (Agilent) spectrophotometer. Spectrophotometric titrations were performed adding a concentrated solution of the host to a more diluted solution of the guest. The apparent stability constants of the pseudorotaxanes were obtained by fitting the absorbance changes with software SPECFIT/ $32,{ }^{[34]}$ according to a $1: 1$ binding model.

Stopped-flow kinetics: Threading kinetics were investigated on airequilibrated $\mathrm{CH}_{2} \mathrm{Cl}_{2}$ (Uvasol) solutions at room temperature by means of a stopped-flow spectrophotometer equipped with a $1 \mathrm{~cm}$ pathlength cell and a driving ram for the mixing system at the $\mathrm{N}_{2}$ pressure of 8.5 bar. Under these conditions, the time required to fill cell is lower than $2 \mathrm{~ms}$. The resulting absorption changes were then analysed with software SPECFIT $/ 32^{[34]}$ to obtain the rate constants for the threading process, according to a mixed order (second order threading-first order dethreading) kinetic model.

\section{Electrochemical Measurements}

Cyclic voltammetric (CV) experiments were carried out in argon-purged dry $\mathrm{CH}_{2} \mathrm{Cl}_{2}$ (Sigma-Aldrich) with an Autolab 30 multipurpose instrument interfaced to a PC. The working electrode was a glassy carbon electrode (Amel, $0.07 \mathrm{~cm}^{2}$ ), carefully polished with an alumina-water slurry on a felt surface, immediately prior to use. The counter electrode was a Pt wire, separated from the solution by a frit, and an Ag wire was employed as a quasi-reference electrode. Ferrocene was present as an internal standard. Tetrabutylammonium hexafluorophosphate was added in a 100-fold proportion with respect to the sample concentration, as supporting electrolyte. Cyclic voltammograms were obtained at sweep rates varying from 0.05 to $5 \mathrm{~V} \mathrm{~s}-1$. The IR compensation implemented within the software was employed to minimize the resistance of the solution. In any instance, the full electrochemical reversibility of the voltammetric wave of ferrocene was taken as an indicator of the absence of uncompensated resistance effects.

\section{Acknowledgements}

The authors thank Centro Interdipartimentale di Misure of the University of Parma for NMR and MS measurements. This work was supported by the Universities of Parma and Bologna and by the European Research Council (ERC) under the European Union's Horizon 2020 research and innovation program (grant agreement no. 692981). CM wishes to thank the CNR of Trieste, and in particular Dr Nicola Demitri, for the single crystal XRD data collected at the ELETTRA synchrotron facility. Chiesi Farmaceutici $\mathrm{SpA}$ is acknowledged for the support with the D8 Venture $\mathrm{X}$-ray equipment.

Keywords: Pseudorotaxanes and Rotaxanes - Calix[6]arenes • 1,2,3-alternate conformation $\cdot X$-ray Structure $\cdot$ Electrochemistry

[1] S. Kassem, T. Van Leeuwen, A. S. A. S. Lubbe, M. R. Wilson, B. L. B. L. Feringa, D. A. D. A. Leigh, Chem. Soc. Rev. 2017, 46, 2592-2621.

[2] E. R. Kay, D. A. Leigh, F. Zerbetto, Angew. Chem. Int. Ed. 2007, 46, 72-191.

[3] V. Balzani, A. Credi, M. Venturi, Chem. - Eur. J. 2002, 8, 5524-5532.

[4] A. Arduini, G. Orlandini, A. Secchi, A. Credi, S. Silvi, M. Venturi, in Calixarenes Beyond (Eds.: P. Neri, J.L. Sessler, M.-X. Wang), Springer International Publishing, Cham, 2016, pp. 761-781. 
[5] A. Arduini, G. Orlandini, A. Secchi, A. Credi, S. Silvi, M. Venturi, in Ref. Module Chem. Mol. Sci. Chem. Eng., Elsevier, 2014, pp. 1-26.

[6] M. Xue, Y. Yang, X. Chi, X. Yan, F. Huang, Chem. Rev. 2015, 115, 7398-7501.

[7] W. Yang, Y. Li, H. Liu, L. Chi, Y. Li, Small 2012, 8, 504-516.

[8] A. Arduini, R. Ferdani, A. Pochini, A. Secchi, F. Ugozzoli, Angew. Chem. Int. Ed. 2000, 39, 3453-3456.

[9] A. Credi, S. Dumas, S. Silvi, M. Venturi, A. Arduini, A. Pochini, A. Secchi, J. Org. Chem. 2004, 69, 5881-5887.

[10] A. Arduini, R. Bussolati, A. Credi, A. Pochini, A. Secchi, S. Silvi, M. Venturi, Tetrahedron 2008, 64, 8279-8286.

[11] F. Ugozzoli, C. Massera, A. Arduini, A. Pochini, A. Secchi CrystEngComm 2004, 6, 227-232.

[12] V. Zanichelli, M. Bazzoni, A. Arduini, P. Franchi, M. Lucarini, G. Ragazzon, A. Secchi, S. Silvi, Chem. - Eur. J. 2018, 24, 12370-12382.

[13] V. Zanichelli, G. Ragazzon, G. Orlandini, M. Venturi, A. Credi, S. Silvi, A. Arduini, A. Secchi, Org. Biomol. Chem. 2017, 15, 6753-6763.

[14] V. Zanichelli, G. Ragazzon, A. Arduini, A. Credi, P. Franchi, G. Orlandini, M. Venturi, M. Lucarini, A. Secchi, S. Silvi, Eur. J. Org. Chem. 2016, 2016, 1033-1042.

[15] A. Arduini, R. Bussolati, A. Credi, S. Monaco, A. Secchi, S. Silvi, M. Venturi, Chem. - Eur. J. 2012, 18, 16203-16213.

[16] A. Arduini, R. Bussolati, A. Credi, A. Secchi, S. Silvi, M. Semeraro, M. Venturi, J. Am. Chem. Soc. 2013, 135, 9924-9930.

[17] A. Arduini, F. Ciesa, M. Fragassi, A. Pochini, A. Secchi, Angew. Chem Int. Ed. 2005, 44, 278-281.

[18] A. Arduini, F. Calzavacca, A. Pochini, A. Secchi, Chem. - Eur. J. 2003 9, 793-799.

[19] J. P. M. van Duynhoven, R. G. Janssen, W. Verboom, S. M. Franken, A Casnati, A. Pochini, R. Ungaro, J. de Mendoza, P. M. Nieto, J. Am. Chem. Soc. 1994, 116, 5814-5822.

[20] R. Lavendomme, D. Ajami, S. Moerkerke, J. Wouters, K. Rissanen, M. Luhmer, I. Jabin, Chem. Commun. 2017, 53, 6468-6471.

[21] J. de Mendoza, M. Carramolino, F. Cuevas, P. M. Nieto, P. Prados, D. N. Reinhoudt, W. Verboom, R. Ungaro, A. Casnati, Synthesis 1994 1994, 47-50.

22] F. P. Gasparro, N. H. Kolodny, J. Chem. Educ. 1977, 54, 258.

[23] V. Amendola, L. Fabbrizzi, L. Mosca, Chem. Soc. Rev. 2010, 39, 38893915.

[24] L. Pescatori, A. Arduini, A. Pochini, F. Ugozzoli, A. Secchi, Eur. J. Org. Chem. 2008, 2008, 109-120.

[25] J. W. Jones, H. W. Gibson, J. Am. Chem. Soc. 2003, 125, 7001-7004.

[26] F. Huang, J. W. Jones, C. Slebodnick, H. W. Gibson, J. Am. Chem. Soc 2003, 125, 14458-14464.

[27] A. E. Kaifer, M. Gómez-Kaifer, Supramolecular Electrochemistry, Wiley, 2008.

[28] A. J. Bard, L. R. Faulkner, Electrochemical Methods: Fundamentals and Applications, 2nd Edition, John Wiley \& Sons, 2000.

[29] CrysAlisPro, Rigaku Oxford Diffraction, 2015.

[30] Sheldrick G. M., SADABS v2.03: Area-Detector Absorption Correction, University Of Göttingen, Germany, 1999.

[31] A. Altomare, M. C. Burla, M. Camalli, G. L. Cascarano, C. Giacovazzo, A. Guagliardi, A. G. G. Moliterni, G. Polidori, R. Spagna, J. Appl. Crystallogr. 1999, 32, 115-119.

[32] G. M. Sheldrick, Acta Crystallogr. A 2008, 64, 112-122.

[33] L. J. Farrugia, J. Appl. Crystallogr. 2012, 45, 849-854.

[34] R. A. Binstead, SPECFIT/32, Fitting Software, Spectrum Software Associates, Chapel Hill, 1996., 1996. 
Entry for the Table of Contents (Please choose one layout)

\section{FULL PAPER}

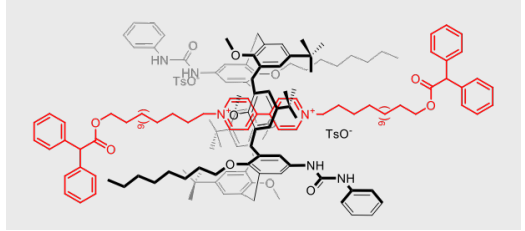

A bis( $N$-phenylureido)calix[6]arene that adopts a 1,2,3-alternate conformation has been synthesised and its structure has been established in solution of low polarity solvents and in the solid state. Its ability to act as a wheel and form interwoven systems with viologen salts was studied through structural characterisation and electrochemical measurements.

\section{Key Topic}

M. Bazzoni, V. Zanichelli, L. Casimiro C. Massera, A. Credi, A. Secchi, * $S$. Silvi, * and A. Arduini*

Page No. - Page No.

New Geometries for Calix[6]arenebased Rotaxanes

*one or two words that highlight the emphasis of the paper or the field of the study 